\title{
Pain Relief Knowledge, History, and Expectations among Emergency Dental Patients
}

\author{
Daniel C. Brawley \\ West Virginia University, dcb0026@mix.wvu.edu
}

Follow this and additional works at: https://researchrepository.wvu.edu/etd

Part of the Endodontics and Endodontology Commons

\section{Recommended Citation}

Brawley, Daniel C., "Pain Relief Knowledge, History, and Expectations among Emergency Dental Patients" (2019). Graduate Theses, Dissertations, and Problem Reports. 7440.

https://researchrepository.wvu.edu/etd/7440

This Thesis is protected by copyright and/or related rights. It has been brought to you by the The Research Repository @ WVU with permission from the rights-holder(s). You are free to use this Thesis in any way that is permitted by the copyright and related rights legislation that applies to your use. For other uses you must obtain permission from the rights-holder(s) directly, unless additional rights are indicated by a Creative Commons license in the record and/ or on the work itself. This Thesis has been accepted for inclusion in WVU Graduate Theses, Dissertations, and Problem Reports collection by an authorized administrator of The Research Repository @ WVU. For more information, please contact researchrepository@mail.wvu.edu. 


\title{
Pain Relief Knowledge, History, and Expectations among Emergency Dental Patients
}

\author{
D. Cade Brawley, D.D.S. \\ Thesis submitted to the \\ School of Dentistry \\ at West Virginia University \\ in partial fulfillment of the requirements \\ for the degree of \\ Master of Science \\ in \\ Endodontics
}
Daniel W. McNeil, Ph.D., Chair
Mark A. Byron, D.D.S., M.S.
Bryan D. Weaver D.D.S., MD

Department of Endodontics

Morgantown, West Virginia

2019

Keywords: acute dental pain, expectations, medication knowledge, dental emergency.

Copyright 2019 D. Cade Brawley 


\title{
Abstract \\ Pain Relief Knowledge, History, and Expectations among Emergency Dental Patients
}

\section{Introduction}

\author{
D. Cade Brawley D.D.S.
}

Dentists frequently treat and manage patients with acute dental pain. Patients often seek care to treat their pain. As a part of that treatment, it is common for providers to use both prescription and non-prescription medications in the management of the patient's dental pain. This study focused on understanding the patient's knowledge, history and expectations regarding prescription and non-prescription medication in the management of their dental pain.

\section{Methods}

A self-report survey was developed, using Likert-type scales, consisting of 32 items, including standardized, psychometrically-tested instruments. The survey was administered to 108 adult outpatients who reported to the West Virginia University School of Dentistry urgent care clinic.

\section{Results}

Expected pain relief ratings of six opioid medications was compared to that of five non-opioid medications (including four that are over-the-counter drugs). Expected relief from opioid medications $(M=7.89, S D=1.86)$ was significantly higher than that of non-opioid medications $(M=4.98, S D=2.0)$, with greater pain relief expected from the opioid medications versus nonopioid ones, $t(37)=7.30, p<.0005$. Across all 108 patients, the average dental pain level, on a 0 -10 scale, was $5.42(S D=2.68)$; of these patients, 39 expected that an opioid prescription would be necessary for their present dental pain relief. A binary logistic regression was conducted with pain level as the predictor and expectation of an opioid as the outcome variable. The model was significant, $\chi^{2}(1, N=108)=9.86, p=.002$, indicating that pain level could distinguish whether patients would expect an opioid medication prescription at their appointment, with higher pain levels associated with greater expectation of an opioid. The expected pain relief rating of opioid medications was compared to the combination of ibuprofen/acetaminophen; the mean for the opioid medications was $7.69(S D=2.23)$, while the mean for ibuprofen/acetaminophen combination mean was $5.92(S D=2.62)$. As predicted, these means differed significantly, with greater pain relief associated with opioid medications, $t(38)=4.12, p<.0005$.

\section{Conclusions}

Patients believe that opioids provide superior dental pain relief than non-opioid medications. With higher dental pain levels, patients' expectation to receive an opioid pain medication is greater. In general, urgent care dental patients have limited knowledge of both opioid and nonopioid analgesic medications. 


\section{Dedication}

I would like to dedicate this research to my family. First and foremost, to my wife Amber who choose to go on this life's journey with me. You inspire me and challenge me to be a better person each and every day. You are the love of my life and I can't describe the excitement I have to live this life with you. To our daughters, Brooke and Bailey. You are rays of light and joy in my life.

To my parents, Danny and Kim Brawley. Your steadfast love and support throughout my life gave me the skills and opportunity to chase my dreams and I am forever grateful. 


\section{Acknowledgments}

I would like to take this opportunity to thank the following people.

Dr. Dan McNeil - Words can't express my gratitude for chairing my committee.

Your guidance, mentorship and expertise took a small idea into meaningful research. Your approach to life inspires me.

Dr. Leigh Speer - Thank you for giving me the chance to become an endodontist. I will never forget the call in which you offered me a spot in the program. I hope to make you proud.

Dr. Keith Hildebrand - Thank you for all your support. Your pride in your state and West Virginia University is palpable. Thank you for sharing it with me for a short time.

Dr. Bryan Weaver - Thank you for your input and support in serving on my committee. Your leadership in the school of dentistry makes it a better place.

Dr. Tom Borgia - Your work, support and guidance of the endodontics department and West Virginia School of Dentistry over the years is immeasurable. Thank you.

Dr. Mark Byron - Thank you for answering the call to lead the program. I have learned much from you and am a better clinician for it.

Dr. Sam Dorn - Your contributions to the field of endodontics is inspirational. I am privileged to get to learn from you over these last few months.

Dr. Mehran Malakpour - You and I hit it off from day one at the interview. There is no better co-resident I could have asked for. The things you have achieved this far in your life are beyond impressive. I am proud to call you my colleague and friend.

Mr. Jonathan Gore - You help with data collection and entry was absolutely invaluable. Your hard work and attention to detail will serve you well and you have a great future ahead of you. 


\section{Table of Contents}

\section{Pain Relief Knowledge, History, and Expectations}

among Emergency Dental Patients.......................................

Abstract....................................................................

Dedications.................................................................

Acknowledgements.........................................................

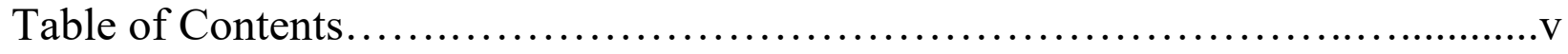

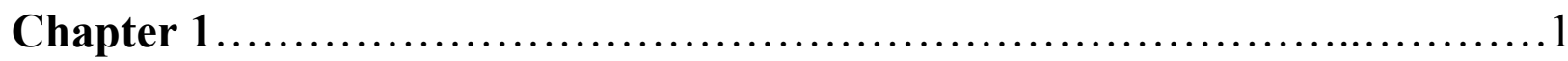

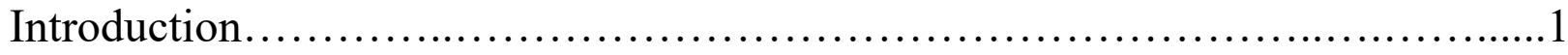

Statement of the Problem....................................................

Significance of the Study ..................................................2

Hypothesis.....................................................................

Definition of Terms.....................................................4

Assumptions............................................................ 5

Limitations............................................................. 5

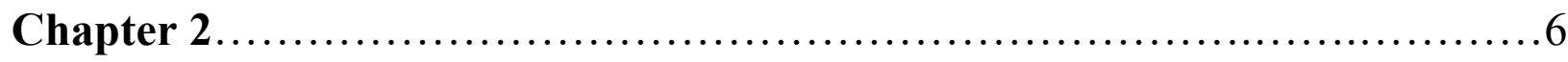

Dental pain management goals.........................................6

Patient Expectations.......................................................

Pain Management Expectations............................................. 8 
Patient Knowledge of Medications........................................ 11

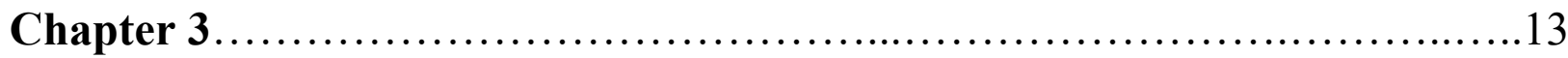

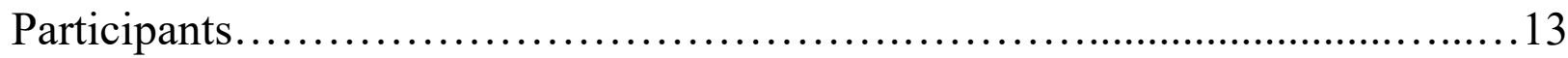

Materials......................................................................

Procedure................................................................. 14

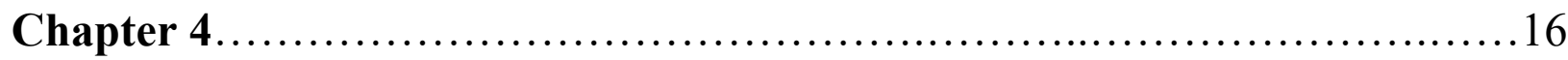

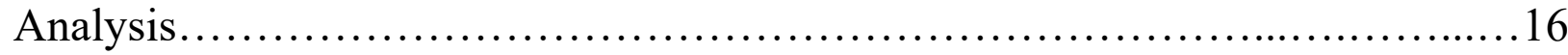

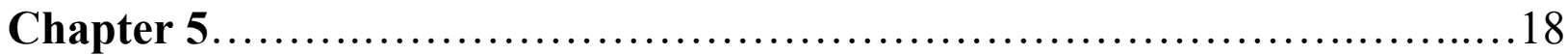

Results......................................................................

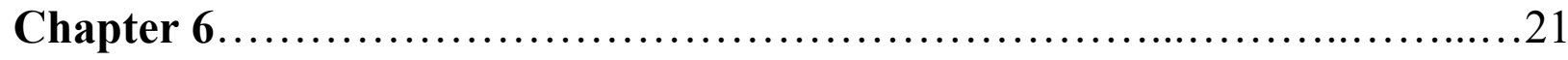

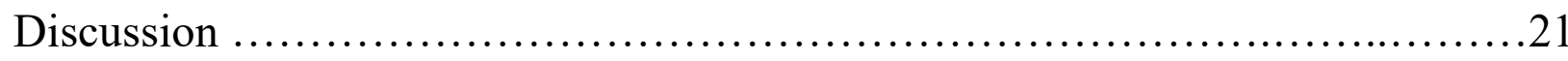

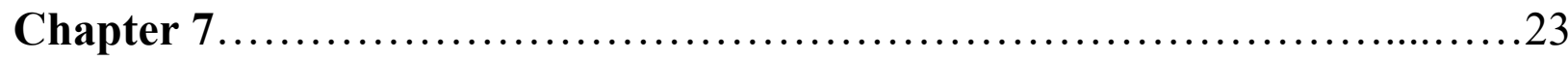

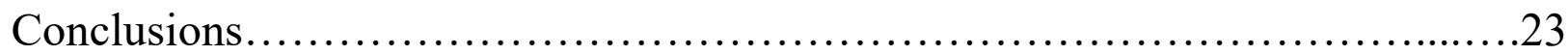

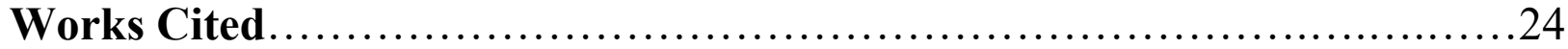

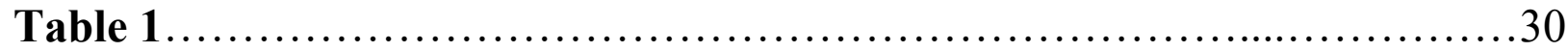

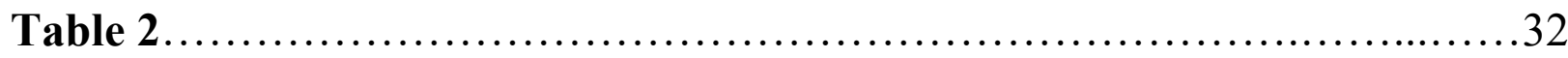

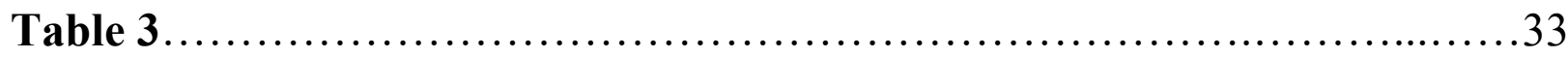

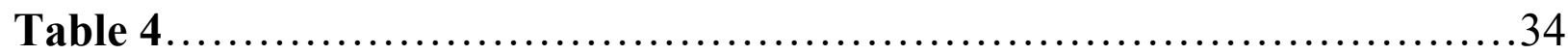




\section{Chapter 1- Introduction}

Over the last 20 years, prescription opioid drug abuse has increased dramatically in the USA.(1) In 2016, over 42,000 individuals died from opioid related overdoses.(2) On October 16, 2017, the United States government declared the opioid epidemic a public health emergency.(2) Researchers estimated that in the year 2013 in the USA, the economic burden of opioid overdose, abuse, and dependence was approximately $\$ 78.5$ billion.(3) The USA comprises about $4 \%$ of the world's population, but consumes $80 \%$ of all opioids and $99 \%$ of all hydrocodone in the world.(4) Opioid overdoses have surpassed cocaine and heroin in overdose deaths.(5) Since 2013, mortality from drug overdose deaths has exceeded motor vehicle accidents.(6) From the years 2009 through 2011, dentists prescribed $8 \%$ to $12 \%$ of all the opioid analgesics in the USA.(7)

It is important to note that dentists are the number one prescribers of opioids in the 10-19 year old age group.(8) Studies also have shown that legitimate opioid use before graduating high school is independently associated with a $33 \%$ increased risk of opioid misuse after graduation.(9) The extraction of third molars ("wisdom teeth") is often the first encounter a young person has with opioids. A recent study in the Journal of the American Medical Association indicated that opioid prescriptions for opioid-naïve adolescents for wisdom tooth extraction lead to a $6.8 \%$ absolute risk increase in persistent opioid use.(10) This number is similar 
to investigations which evaluated persistent opioid use after major and minor surgical procedures, which was $5.9 \%$ to $6.5 \%$ respectively. The opioid epidemic is currently at a crisis level in the USA, requiring all health care professions to examine their prescribing practices.(2)

\section{Statement of the Problem}

Oral health providers may perceive a need to prescribe prescription opioid medications due to patients' desires. The literature is void, however, of any research on patient perceptions of opioid pain medications in the dental setting for management of acute dental pain. Moreover, patient knowledge of medications to alleviate dental pain is unknown, and it is unclear if patients with acute dental pain in the current climate expect opioid pain medications to manage their dental pain. The effect of prior history of opioid use of patients on desire for pain relief using opioid medications also is unknown in the dental setting.

\section{Significance of the Study}

Review of the literature revealed no studies completed on patient expectations of opioid medications for acute dental pain. Studies have shown that a combination of ibuprofen/acetaminophen has greater pain relief than opioids or drug combinations containing opioids; it is unclear why dentists sometimes prescribe opioid containing pain relievers as a first-line prescription in the management of dental pain.(11) It could postulated that this practice arises from training history, 
pharmaceutical influence, or perceived patient desires for opioid pain medications. Additionally, studies have shown that the pharmaceutical industry's interactions with physicians and dentists affect their prescribing practices and professional behavior.(12) This study is intended to investigate patient perceptions and expectations in the prescription of opioid and other pain-relieving medications in the dental setting.

\section{Hypotheses}

H1: Patients are predicted to report that opioids are the most efficacious pain relievers for dental pain.

H2: Greater current pain level in patients are anticipated to be associated with greater expectation about receiving an opioid pain medication at the time of appointment.

H3: It is predicted that the majority of patients will believe that opioids provide superior dental pain relief relative to an ibuprofen/acetaminophen combination. H4: Patients who have a history of opioid use will have increased likelihood of expecting opioids for pain relief associated with dental care.

H5: Patients with greater medication knowledge are predicted to have an increased likelihood of expecting opioids for pain relief associated with dental care. (It is assumed that very few patients will have knowledge of the data that suggests that 
the ibuprofen/acetaminophen combination may be the most effective for some forms of dental pain.)

\section{Definition of Terms}

Acute pain - "Pain related to acute injury, harm, or repair, and often shorter duration (typically less than 30 days). The cause may be known or unknown. Acute pain usually occurs as part of a single and treatable event. It is often (not always) associated with autonomic nervous system responses (e.g., tachycardia, hypertension, diaphoresis"(13), pain that arises quickly, usually in response to a readily identifiable injury or pathology, and that lasts a relatively short period of time.(14)

Acute exacerbation of a recurring painful condition - "Pain can occur over any duration of time. Pain is due to chronic, organic nonmalignant pathology. Examples of diagnoses that include acute exacerbation of a recurring painful condition are the following: sickle cell pain episodes and migraine headache. There are pain-free episodes between the exacerbations"(13)

Acetaminophen - "A crystalline compound $\mathrm{C}_{8} \mathrm{H}_{9} \mathrm{NO}_{2}$ that is a hydroxy derivative of acetanilide and is used in chemical synthesis and in medicine instead of aspirin to relieve pain and fever."(15)

Cancer pain - "Pain caused by "conditions that are potentially life-threatening." The causes of cancer pain are cancer itself, treatment of cancer, and concurrent disease. Examples of cancer pain include the following: cancer of the pancreas, spinal cord compression caused by tumor infiltration, postsurgical pain associated with cancer treatment, and postmastectomy syndrome"(13)

Chronic/persistent pain - "Chronic (persistent) pain is pain that lasts longer than the expected time of healing. There is continuous pain or the pain recurs at intervals for months or years. In some cases, there are acute exacerbations of chronic pain problems. The cause is often unknown. Examples of chronic or persistent pain include the following: low back pain, diabetic neuropathy, postherpetic neuralgia, multiple sclerosis, and phantom pain"(13)

Hydrocodone - "A semisynthetic narcotic analgesic and antitussive agent that is similar to but more potent than, codeine."(16) 
$\underline{\text { NSAIDs }-~ " P h a r m a c o l o g i c a l ~ a g e n t s ~ t h a t ~ i n h i b i t ~ t h e ~ c y c l o o x y g e n a s e ~ p a t h w a y . "(16) ~}$

Opioid - "Pharmacologic agents that bind to opioid receptors thereby mimicking the action of morphine; opioid agonists induce analgesia, sedation, euphoria, dysphoria, emesis, constipation, respiratory depression and addiction."(16)

Pain - "Sensation of discomfort, distress or agony resulting from the stimulation of specialized nerve endings."(17)

Perception - "An awareness of one's surroundings that is produced by the operation of the senses; intuitive discernment; insight or understanding."(18)

\section{Assumptions}

1. Patients want a way to reduce or eliminate their pain when they seek care for acute dental pain.

2. Patients believe that medications are a crucial part of their pain management.

\section{Limitations}

1. Self-report has limitations in terms of validity and reliability.

2. Patients with extreme acute dental pain may not have wanted to participate in completing the survey associated with this study. 


\section{Chapter 2 - Literature Review}

\section{Dental pain management goals}

Expectations about pain management and relief are crucial in understanding patient behavior in the dental setting. Dental pain is often the primary motivating factor for patients to seek dental treatment.(19) Dental pain can arise from many different diseases, conditions, trauma, or from dental treatment itself.(19) The 3D's principle has been traditionally used to guide the management of dental pain. This approach refers to diagnosis, dental treatment, and drugs in the management of dental pain.(19) Diagnosis allows for the proper evaluation of the condition that is causing the pain. Once a proper assessment is made, the appropriate dental treatment can then be selected that will address the source of the condition. Drugs are used as an adjunct to the dental treatment to aid in the elimination of the etiology causing the pain and in the management/prevention of pain from the procedure itself. Local anesthetics allow for specific areas of the oral cavity to be anesthetized so that dental procedures can be performed comfortably. Such anesthesia allows for the removal of the noxious stimulus that is causing the source of the patient's discomfort.

In other approaches to pain management, antibiotics often are used to aid in the elimination of bacteria along with their toxins which maybe causing patient discomfort. Pain relievers also are often used in an attempt to relieve the noxious 
stimulus itself or from the dental treatment provided, such as a dental extraction, which may induce discomfort. Fundamentally, dentists seek to identify the source of the patient's pain, use appropriate techniques and local anesthetics to comfortably provide treatment to the patient, and use medications as needed in the post-operative management of patient's dental pain. The goal of managing patients with dental pain is to remove the source of their discomfort in the gentlest way possible so that the patient can heal and be free of any dental oral-facial pain or infection.

\section{Patient Expectations}

Expectations are individual beliefs about how events may or should occur in the future.(20) Developed from personal knowledge and experiences (20), expectations can be a powerful influencing factor in one's decisions and even on the behavior of others. In Rosenthal and Jacobson's classic study, teachers were led to have higher expectations for particular student's performance which actually led to enhanced performance for those particular students. This phenomenon contrasts with the Golem effect in which lower expectations placed on an individual leads to lower performance.(21)

"Perhaps, the best known and most extensively studied example of the power of expectation of pain is placebo analgesia".(22) In the 1970's, a series of studies was conducted in which patients were experiencing pain reduction from a 
placebo infusion of saline. An opiate antagonist naloxone was given and a dose dependent increase in pain was observed.(23) "This observation was later confirmed when the open administration of a saline placebo was compared with its hidden administration".(22) The open administration, as expected, was more effective than the hidden placebo administration. These studies gave foundational knowledge of how endogenous opioids and the power of expectation in the form of a placebo can bring about pain reduction.

In a review of more current research involving patients with chronic pain, it was observed that: “A growing body of literature suggests that patients' pretreatment expectations, or the estimated probability associated with a given outcome, predict numerous health outcomes. Generally, studies have shown that patients who forecast positive outcomes are more likely to improve than patients with less optimistic expectations".(24) Expectations play an important role in the management of pain and health related outcomes.

\section{Pain Management Expectations}

The American College of Emergency Physicians classifies pain as acute, acute exacerbation of a recurring painful condition, chronic persistent pain, or cancer pain.(13) The distinction between acute and chronic pain is the most common differentiation and perhaps the most useful. Chronic pain is defined as 
pain with a duration lasting more than 3-6 months.(25) Patients generally have high expectations for the management of chronic pain.(26)

In one study, chronic pain patients were asked about their desired pain level reduction after treatment and indicated that they wished for up to $98 \%$ pain reduction. When asked what they actually expected their pain relief to be, they reported expected pain reductions of 50\%.(26) For chronic pain patients, there is a large disparity between their desired pain reduction and their expected pain reduction. This appears in contrast to patients seeking care in emergency departments for pain in which patients reported an expectation of $72 \%$ pain reduction.(27) Patients seeking emergency dental care appear to have two main concerns in seeking treatment.(28) The first concern and highest expectation for these patients was relief from symptoms, with the second concern being an understanding of the cause of the problem with the hope that it was not a more serious condition. For both chronic pain patients and acute patients with dental pain, the reduction of pain is a high concern and expectation of treatment. $(26,28)$

The literature is lacking regarding patient knowledge on the effectiveness of medications at relieving dental pain. We have limited understanding of how pain levels influence patient expectations and no understating as to whether patients understand or believe evidence-based recommendations for dental pain management recommendations. Patients appear to have a wide array of beliefs in 
regard to opioid pain medications. Chronic pain patients interviewed in a study evaluating opioid versus nonopioid pain management for musculoskeletal pain provided some of the following quotes:

“There's a reason it's controlled—usually because it's better. So in my mind, when you're in serious pain, you need serious medication-which, serious medication is opioids."(29)

"I definitely wanted the opiate [group] .. I guess I was just thinking that it would be stronger medicine."(29)

There were also several comments expressing concerns about the addictive potential of opioid pain medications.

"I had hesitations about the opioid group. . . . I was concerned about longterm use, addiction issues, because, you know, if you feel that good, are you really going to want to stop, ever? And I can answer that honestly, no, you don't want to stop. You feel good."(29)

"I had an opinion that I didn't want to end up on anything that could become addictive. Hydrocodone works. I'm not going to say it doesn't. But if every time I took one I was afraid, oh my God, would this be the one that makes me addicted?"(29)

While some participants reported negative concerns about addictive potential and side effects of opioids, no one seemed concerned about not being 
effective enough or missing out on the non-opioid group which might get better pain relief.(29) Based on this study, it can be concluded that, for musculoskeletal pain patients, there is the general perception that opioids are stronger and better drugs but they might be addictive. It is unknown as to what the perceptions are of dental patients with acute dental pain and their expectations for pain management.

\section{Patient Knowledge of Medications}

"Adequate patient knowledge about medications is necessary for appropriate drug taking behavior"(30) There are no universal parameters however, of what constitutes adequate patient knowledge. Some categories of patient knowledge assessment include drug name, dose, when to take the medication, side effects, and purpose of the medication, among others. Numerous studies across the medical and dental literature indicate that patients' general medication knowledge is poor. In a survey of patient's seeking care at an emergency department, only $48 \%$ could accurately report the current medications that they were taking.(31) One could conclude that if you can't even report the drug that you are taking, you probably have limited knowledge about other aspects of the drug itself. Many times patients' own physicians and pharmacists are not aware of all of the medications their patients are taking.(32)

Patients with dental pain who are self-medicating with over-the-counter medications appears to have very limited knowledge and are at a great risk of 
overdosing on these medications. In a survey of patients seeking emergency dental services, only $42.9 \%$ of patients knew the maximum daily dose and $62.2 \%$ were exceeding the maximum daily dose.(33) A British study observed all of the hospital admissions for accidental acetaminophen overdose over a 24 month period. Of those patients, $41 \%$ were related to dental pain.(34) It appears that a large number of patients don't know all of the medications they take along with the high potential to overdose on over the counter medications. This provides a significant challenge for the provider to make appropriate drug pain management recommendations. It also highlights the need for clear accurate patient instructions for any drugs either prescribed or over the counter recommendations. 


\section{Chapter 3 - Methods and Materials}

\section{Participants}

There were 110 participants, all of whom were outpatients reporting for dental care at the West Virginia University School of Dentistry's Urgent Care Clinic. There were two surveys removed due to validity issues (i.e., apparent cognitive limitations for one patient, and more than $30 \%$ missing data for another patient). There were an additional 12 potential participants who were invited to participate, but who declined to volunteer. Of the 108 useable surveys, there were $60(55.6 \%)$ females, $47(43.5 \%)$ males, and one (0.9\%) identified as other, with an age range of $19-81, M=39.3, \mathrm{SD}=15.0$. The reported race/ethnicity of the participants was: 97 (89.9\%) White/Caucasian, 5 (4.6\%) Black/African American, $1(0.9 \%)$ Hispanic, $3(2.8 \%)$ Asian, $1(.9 \%)$ other, and 1(0.9 \%) who did not answer. Marital status was as follows: 53 (49.1\%) Single, 34 (31.5\%) Married, 5 (31.5\%) Live-in partner, 2 (1.9\%) Separated, 14 (13\%) Divorced. Various demographic and clinically-related information about participants is presented in Table 1.

\section{Materials}

A self-report survey was developed, consisting of 32 items, some with subsections. The survey included previously developed and validated Likert-type questionnaires as well as some questions developed specifically for this study. For 
questions about medications, patients were provided the space to not make a rating, but instead to indicate "not familiar with this drug."

A four-item Medication Knowledge Test was developed for the current investigation, as existing instruments were too long or not specifically focused on the present research questions. For this test, there were seven possible choices across the four items that were correct. A total score, therefore, was calculated based on the number of correct answers ranging from 0 to 7.

For demographic questions and assessment of dental utilization, questions were utilized from the 2012 National Health and Nutrition Examination Survey.(35)

The Defense and Veterans Pain Rating Scale was utilized to assess the patients' current pain level.(36) The format for questions about current and past chronic and acute pain were based in part on the work of Cleeland (1989).(37)

A single item was utilized to assess patients' dental care-related anxiety and fear, using the omnibus item from the Dental Fear Survey.(38) In addition, a fouritem assessment developed by Quentin and colleagues was utilized to access distress associated with pain in general.(39)

\section{Procedure}

An undergraduate research assistant was trained and included in the IRB protocol to help with the data collection process. Data were collected over a period of 3 months, from July 5, 2019 through October 4, 2019. 
Patients were approached after indicating to the receptionist a willingness to complete the survey in the waiting area after they registered for the Urgent Care Clinic at the West Virginia University School of Dentistry. After obtaining written informed consent, patients completed the survey on paper in the waiting area, using a provided clipboard and pen. Upon completion, each patient was thanked and given a $\$ 10$ (ten dollar) gift card, which they acknowledged via signing a receipt form. 


\section{Chapter 4 - Analyses}

H1: Patients were predicted to report that opioids are the most efficacious pain relievers for dental pain.

The five opioid medications were grouped together, and mean value calculated for anticipated pain relief, based on a 0-10 scale. A similar process was used to develop a mean for the five non-opioid medications. A paired-sample $t$ test was used to compare the rating for the opioid medications with non-opioid ones.

H2: Greater current pain level in patients was anticipated to be associated with greater expectation about receiving an opioid pain medication at the appointment.

A binary logistic regression was conducted, with current pain level as a predictor, and expectation of an opioid medication as the outcome variable.

H3: It was predicted that the majority of patients would believe that opioids would provide superior dental pain relief relative to an ibuprofen/acetaminophen combination.

Similar to H1, the five opioid medications were grouped together, and mean value calculated for anticipated pain relief, based on a 0-10 scale. A paired-sample $t$ test was used to compare the rating for the opioid medications with the rating for the ibuprofen/acetaminophen combination. 
H4: Patients who have a history of opioid use were predicted to have an increased likelihood of expecting opioids for pain relief associated with dental care.

A Chi-square analysis was conducted, grouping patients into those with and without a history of opioid use, as well as those who are or were not expecting that an opioid will be the best medication to manage their dental pain.

H5: Patients with greater medication knowledge were predicted to have an increased likelihood of expecting opioids for pain relief associated with dental care. A regression analysis was conducted, with medication knowledge as a predictor, and expectation of an opioid medication as the outcome variable. 


\section{Chapter 5 - Results}

\section{Hypothesis 1}

Only 38 of the 108 patients reported sufficient knowledge to evaluate all 11 of the opioid and non-opioid medications; this analysis is based solely on the responses of those patients. The expected pain relief rating of the five opioid medications was compared to that of the six non-opioid medications. The mean for the opioid medication pain relief was $7.89(\mathrm{SD}=1.86)$, while the non-opioid mean was $4.98(\mathrm{SD}=2.0)$. As predicted, the means differed significantly, with greater pain relief expected from the opioid medications versus non-opioid ones, $t(37)=$ $7.30, p<.0005$.

\section{Hypothesis 2}

Of the 108 patients, the average dental pain level, on a $0-10$ scale, was 5.42 $(S D=2.68)$; of these patients, 39 expected that an opioid prescription would be necessary for pain relief. A binary logistic regression was conducted with pain level as the predictor and expectation of an opioid as the outcome variable. The model was significant, $\chi^{2}(1, \mathrm{~N}=108)=9.86, p=.002$, indicating that pain level could distinguish whether patients would be expecting an opioid medication prescription at their appointment. The model explained between $8.7 \%$ (Cox and Snell R square) and $11.9 \%$ (Nagelkerke R square) of the variance in opioid 
expectation status, and correctly classified $65.7 \%$ of the patients. Table 2 presents the results of the regression, indicating that higher pain levels were associated with a greater likelihood of being in the group that expected to receive a prescription for an opioid medication.

\section{Hypothesis 3}

There were 39 patients $(36.1 \%)$ who reported sufficient knowledge of the five opioids and the ibuprofen/acetaminophen combination to allow analysis. The expected pain relief rating of opioid medications was compared to the combination of ibuprofen/acetaminophen. The mean for the opioid medications was 7.69 (SD $=$ 2.23), while the mean for ibuprofen/acetaminophen combination mean was 5.92 $(\mathrm{SD}=2.62)$. As predicted, the means differed significantly, with greater pain relief associated with opioid medications, $t(38)=4.12, p<.0005$.

\section{Hypothesis 4}

Patients who reported any prior history of use of an opioid medication $(n=$ $81 ; 75.0 \%)$ were compared to those who did not report such use $(n=27 ; 25 \%)$ in terms of their expectation of receiving an opioid medication prescription at their appointment. A 2 X 2 Chi-square analysis was conducted but did not reach statistical significance, $\chi^{2}(1, N=108)=3.01, p=.107$, so the hypothesis could not be confirmed. Table 3 presents the data. 


\section{Hypothesis 5}

The Pain Medication Knowledge Test score was calculated for each of the 108 patients, resulting in a mean of $5.1(S D=2.1)$, based on the $0-7$ scale. Thirty eight $(35.2 \%)$ of the patients had a total score of 7 , indicating a perfect score on this instrument. A binary logistic regression was conducted with the Pain Medication Knowledge score as the predictor and expectation of an opioid as the outcome variable. The model was not significant, $\chi^{2}(1, N=108)=1.38, p=.24$, so the hypothesis could not be confirmed. Table 4 presents the results of the regression. 


\section{Chapter 6 - Discussion}

It is believed that this survey was the first one developed and administered to investigate expectations of pain management and knowledge of pain management medications of dental patients seeking urgent dental care. Results indicated that patients believe that opioid pain medications will provide a greater level of pain relief than non-opioid medications. More specifically, patients believed that opioids will provide greater pain relief than an ibuprofen/acetaminophen combination. This belief is at odds with the scientific literature that indicates that the ibuprofen/acetaminophen combination provides superior pain relief.(11) This results in an interesting dynamic in that the patient's expectation of what would provide them with the greatest pain relief may not yield the best results.

Furthermore, opioid pain medications carry a significant risk of addiction without superior pain relief of OTC pain medication combinations. Identifying this knowledge gap for the first time identifies the need to educate patients on their dental pain management recommendations.

It was also discovered that the greater the patient's current pain level, the greater the expectation that they will require an opioid pain medication at the appointment. Results indicated that as the pain level increased, the expectation to receive an opioid pain medication also increased. This information may be vital to 
clinicians to understand how patients' pain level influences their expectations and likely their ultimate satisfaction with treatment.

The most telling aspect of data analysis was the general lack of knowledge patients had of common OTC medications, as well as a significant lack of knowledge of opioid pain medications. Only $35 \%$ of patients reported sufficient knowledge to be able to evaluate all 11 of the opioid and non-opioid medications. For the clinicians who deal with these classes of medications every day, it is important to understand that patients are not familiar with them. This understanding will help to better direct patient education in their dental pain management recommendations. 


\section{Chapter 7 - Conclusions}

This study was the first to examine emergency dental patients' pain relief knowledge, history, and expectations regarding their pain management. Patients associated greater pain relief with opioids versus non opioid medications. Higher pain levels were associated with a greater likelihood of expecting to receive an opioid pain medication. Patients incorrectly believed that opioids provide greater pain relief over an ibuprofen/acetaminophen combination. These results reveal that a significant proportion of dental patients have quite limited knowledge about analgesic medications that can be used to alleviate dental and other pain. This lack of knowledge is a vulnerability, in that patients may be unaware of the power of OTC medications, as well as the risk of addiction for opioids. Future research could explore the inclusion of analgesic knowledge as a component of oral health literacy. 


\section{References}

1. Cicero TJ, Ellis MS, The prescription opioid epidemic: a review of qualitative studies on the progression from initial use to abuse. Dialogues Clin Neurosci 2017;19(3):259-69.

2. Jones O, Viswanath J, Peck AD, Kaye JS, Gill TT, Simopoulos MR. A brief history of the opioid epidemic and strategies for pain medicine. Pain Therapy 2018 Doi: 10.1007/s40122-018-0097-6.

3. Gupta N, Vujicic M, Blatz A. Opioid prescribing practices from 2010 through 2015 among dentists in the United States. J Am Dent Assoc 2018;149:237-245.e6. Doi: 10.1016/j.adaj.2018.01.005.

4. Becker DE. Pain Management: Part 1: Managing acute and postoperative dental pain. Anesth Prog 2010;57(2):67-79. Doi: 10.2344/0003-3006-57.2.67.

5. Meyer R, Patel AM, Rattana SK, Quock TP, Mody SH. Prescription opioid abuse: A literature review of the clinical and economic burden in the United States. Population of Health Management 2014;17(6):372-87. Doi: 10.1089/pop.2013.0098.

6. Williams AR, Bisaga A. Perspective 814 From aids to opioids-how to combat an epidemic. N Engl J Med 2016. Doi: 10.1056/NEJMp1604223.

7. Jimoh KO, Matthews DC, Brillant M, Sketris I. Pattern of opioid analgesic prescription for adults by dentists in Nova Scotia, Canada. JDR Clin Transl 
Res 2018;3(2):203-11. Doi: 10.1177/2380084418761330.

8. Volkow ND, Mclellan TA, Cotto JH, Karithanom M, Weiss SRB.

Characteristics of Opioid Prescriptions in 2009. JAMA 2011;305(13):1299301. Doi: 10.1001/jama.2011.401.

9. Miech R, Johnston L, O’Malley PM, Keyes KM, Heard K. Prescription opioids in adolescence and future opioid isuse. Pediatrics 2015;136(5):e1169-77. Doi: 10.1542/peds.2015-1364.

10. Schroeder AR, Dehghan M, Newman TB, Bentley JP, Park KT. Association of opioid prescriptions from dental clinicians for US adolescents and young adults with subsequent opioid use and abuse. JAMA Internal Medicine 2018;94305:1-8. Doi: 10.1001/jamainternmed.2018.5419.

11. Moore PA, Ziegler KM, Lipman RD, Aminoshariae A, Carrasco-Labra A, Mariotti A. Benefits and harms associated with analgesic medications used in the management of acute dental pain. J Am Dent Assoc 2018;149:256-265.e3.

Doi: 10.1016/j.adaj.2018.02.012.

12. Fisher MA. Physicians and the pharmaceutical industry: a dsfunctional relationship. Perspect Biol Med 2003;46(2):254-72. Doi: 10.1353/pbm.2003.0019.

13. Physician credentialing and delineation of clinical privileges in emergency medicine. Ann Emerg Med 2017;September(Vol 70 No.3). Doi: 
10.1016/j.annemergmed.2017.06.029.

14. Albery IP, Munafo M. Key concepts in health psychology. London, UK:

Sage UK. Retrieved from

http://www.libproxy.wvu.edu/login?url=https://search.credoreference.com/co ntent/entry/sageukhp/pain_and_acute_pain/0?institutionId=735

15. Merriam-Webster's Medical Dictionary, edited by

Merriam-Webster, 1st edition, 2016. Credo Reference,

http://www.libproxy.wvu.edu/login?url=https://search.credoreference.com/co ntent/entry/mwmedicaldesk/acetaminophen/0?institutionId=735. Accessed 18 Nov. 2019.

16. Berman LH, Doyle SL, Goodell GG, Krell KV, Odom, MA. Glossary of Endodontic Terms Ninth Edition p. 4

17. Anderson D.M., Novak P.D., Elliott M.A. Dorland's Illustrated Medical Dictionary. Philadelphia, PA: W.B. Saunders Company; 1994 p.1215

18. Allen RE. The penguin English Dictionary (3rd ed.). London, UK: Penguin. Retrieved from

http://www.libproxy.wvu.edu/login?url=https://search.credoreference.com/co ntent/entry/penguineng/perception/0?institutionId $=735$

19. Hargreaves K, Abbott P V. Drugs for pain management in dentistry. Aust Dent J 2005;50:22. 
20. Expectations (Social Psyphology) - IResearchNet. Available at: https://psychology.iresearchnet.com/social-psychology/socialcognition/expectations/. Accessed April 1, 2019, n.d.

21. Babad EY, Inbar J, Rosenthal R. Pygmalion, galatea, and the golem : investigations of biased and unbiased Teachers. Journal of Educational Psychology 1982;74(4):469-74.

22. Fields HL. How expectations influence pain. Pain 2018;159(9).

23. Levine JD, Gordon NC, Fields HL. Naloxone dose dependtly produces analgesia and hyperalgesia in postoperative pain.Nature 1979;278:740-741.

24. Rainville P. Expectations predict chronic pain treatment outcomes. Pain 2016;157(2).

25. Treede RD, Rief W, Barke A, A classification of chronic pain for ICD-11. Pain 2015;156(6):1. Doi: 10.1097/j.pain.0000000000000160.

26. Geurts JW, Willems Paul C, Lockwood C, van Kleef M, Kleijnen J, Dirksen C. Patient expectations for management of chronic non-cancer pain: A systematic review. Heal Expect 2017;20(6):1201-17. Doi: 10.1111/hex.12527.

27. Fosnocht DE., Heaps ND., Swanson ER. Patient expectations for pain relief in the ed. Am J Emerg Med 2004;22(4):286-8. Doi:

10.1016/j.ajem.2004.04.011. 
28. Anderson R. Patient expectations of emergency dental services: a qualitative interview study. Br Dent J Vol 2004;197(6). Doi: 10.1038/sj.bdj.4811652.

29. Matthias MS., Donaldson MT, Jensen Agnes C, Krebs E. "I was a little surprised": qualitative insights from patients enrolled in a 12-month trial comparing opioids with nonopioid medications for chronic musculoskeletal pain. J Pain 2018;19(9):1082-90. Doi: 10.1016/j.jpain.2018.04.008.

30. Frank JA, Kirscht JP, Shimp LA. An assessment of different components of patient medication knowledge. Published by : Lippincott Williams \& Wilkins Stable URL : https://www.jstor.org/stable/3764501 An Assessment of D 2019;24(11):1018-28.

31. Vilke GM, Iskander J, Chan TC. Emergency Department Patient knowledge of medications. J Emerg Med. 2000;19(4):327-30.

32. Torrible SJ, Hogan DB. Medication use and rural seniors: who really knows what they are taking ? Can Fam Physician1997;43:893-8.

33. Hommez G, Ongena B, Cauwels RGEC, Paepe P, Christiaens V, Jacquet W. Analgesia ( mis ) usage on a dental emergency service : a patient survey. Clin Oral Investig 2018:1297-302.

34. Siddique I, Mahmood H, Mohammed AR. Paracetamol overdose secondary to dental pain: a case series. Br Dent J 2015;219(6):E6-E6. Doi: 10.1038/sj.bdj.2015.706. 
35. Nhanes 2015-2016: Oral Health Data Documentation, Codebook, and Frequencies. Available at: https://wwwn.cdc.gov/Nchs/Nhanes/20152016/OHQ_I.htm. Accessed May 6, 2019, n.d.

36. Polomano RC, Galloway KT, Kent ML. Psychometric testing of the defense and veterans pain rating scale (DVPRS): A new pain scale for military population. Pain Med (United States) 2016;17(8):1505-19. Doi: $10.1093 / \mathrm{pm} / \mathrm{pnw} 105$.

37. Cleeland C.S. Measurement of pain by subjective report In C. R. Chapman \& J. D. Loeser (Eds.). Adv Pain Res Ther n.d.;12 Issues:391-403.

38. Kleinknecht RA, Klepac RK, Alexander LD. Origins and characteristics of fear of dentistry. J Am Dent Assoc 1973;Apr:86(4):842-8.

39. Quentin LL, Wright Casey D, Nelson CI, Arias MC, Mittinity MM, McNeil DW. 2019, Manuscript submitted for publication development and validation of the brief assessment of distress about pain (bapd). n.d. 
Table 1.

Demographic characteristics for the study sample

$N(\%) /$ Mean $(S D)$

Gender $(n=108)$

Men

$60(55.6 \%)$

Women

$47(43.5 \%)$

Other

$1(0.9 \%)$

Age $(n=108)$

$39.3(15.0)$

(Range 19-81 years)

Race/Ethnicity $(n=108)$

White

Black/African American

$97(89.89 \%)$

Hispanic/Latino

Asian American

Native American/Pacific Islander

Other

$5(4.6 \%)$

$1(0.9 \%)$

$3(2.8 \%)$

$0(0 \%)$

$1(0.9 \%)$

Years of Education $(n=106)$

$13.23(2.5 \%)$

(Range 3-20 years)

Annual Household Income $(n=108)$

Less than 10,000

10,000 to 14,999

$19(17.6 \%)$

15,000 to 24,999

$19(17.6 \%)$

$14(13.0 \%)$

25,000 to 34,999

$13(12.0 \%)$

35,000 to 49,999

$15(13.9 \%)$

50,000 to 74,999

$13(12.0 \%)$

75,000 to 99,999

$9(8.3 \%)$

100,000 to 149,999

$1(.9 \%)$

150,000 to 199,999

$3(2.8 \%)$

200,000 or more

$2(1.9 \%)$ 
Table 1 (continued)

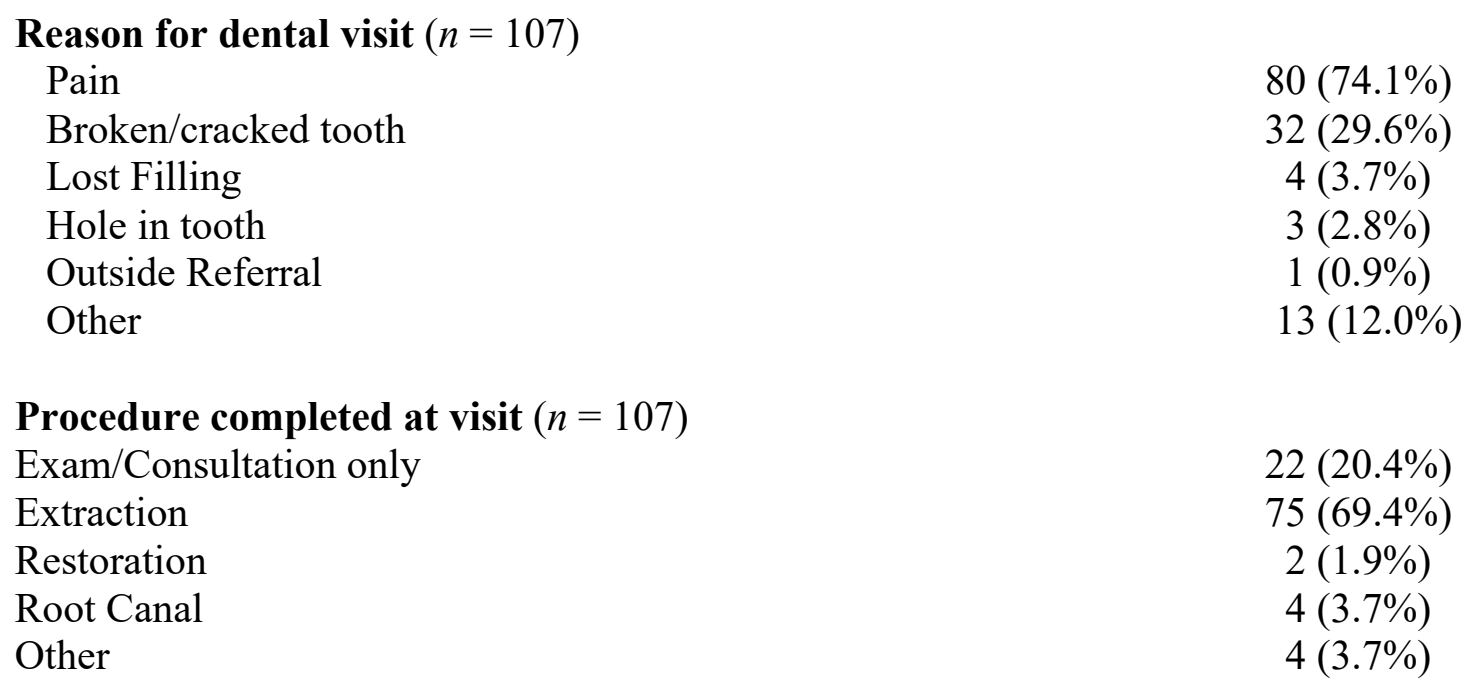

History of Medications Prescribed/Recommended in Past Dental Visits $(n=107)$ Amoxicillin $500 \mathrm{mg}$ $8(7.2 \%)$ Clindamycin Augmentin 875mg

Azithromycin $3(2.7 \%)$

Penicillin VK

$1(0.9 \%)$ $1(0.9 \%)$

Hydrocodone + Acetaminophen $3(2.7 \%)$ Ibuprofen Vicoprofen $32(28.8 \%)$

Tylenol \#3 $8(7.2 \%)$ $1(0.9 \%)$ $1(0.9 \%)$

Prevident 5000 $4(3.6 \%)$ Peridex $0.12 \%$

Medications Prescribed/Recommended at Current Dental Visit $(n=107)$

Amoxicillin $500 \mathrm{mg}$

Hydrocodone + Acetaminophen

Ibuprofen $800 \mathrm{mg}$

Tramadol $50 \mathrm{mg}$

$2(1.9 \%)$

Tylenol $500 \mathrm{mg}$

$2(1.9 \%)$

Peridex $0.12 \%$

$1(0.9 \%)$

$1(0.9 \%)$

$5(4.6 \%)$

Note. Some percentages add up to more than $100 \%$ as individual patients were prescribed/recommended more than one medication. All prior medications for any dental visit were recorded for each patient. 
Table 2.

Logistic Regression with Current Dental Pain Level Predicting the Likelihood of Expecting an Opioid Medication

\begin{tabular}{|c|c|c|c|c|c|c|c|c|c|}
\hline \multicolumn{10}{|c|}{ Variables in the Equation } \\
\hline & & \multirow[b]{2}{*}{ B } & \multirow[b]{2}{*}{ S.E. } & \multirow[b]{2}{*}{ Wald } & \multirow[b]{2}{*}{ df } & \multirow[b]{2}{*}{ Sig. } & \multirow[b]{2}{*}{$\operatorname{Exp}(B)$} & \multicolumn{2}{|c|}{$95 \%$ C.Ifor EXP(B) } \\
\hline & & & & & & & & Lower & Upper \\
\hline \multirow[t]{2}{*}{ Step $1^{\text {a }}$} & $\begin{array}{l}16 \text { - current level of dental } \\
\text { pain }\end{array}$ & .254 & .087 & 8.522 & 1 & .004 & 1.290 & 1.087 & 1.530 \\
\hline & Constant & -1.932 & .556 & 12.074 & 1 & .001 & .145 & & \\
\hline
\end{tabular}

a. Variable(s) entered on step 1: 16- current level of dental pain.

Note. $N=108$ 
Table 3.

Chi Square Analysis of the Interaction of History of Opioid Use and Expectation of Receiving an Opioid Medication

\begin{tabular}{llr|r|r} 
& & \multicolumn{2}{c}{ History of Opioid Use } & \multicolumn{1}{c}{} \\
& & No & Yes & \multicolumn{1}{c}{ Total } \\
\hline Expectation of & No & 21 & 48 & 69 \\
\cline { 2 - 5 } Receiving Opioid & Yes & 6 & 33 & 39 \\
\hline Total & & 27 & 81 & 108 \\
\hline
\end{tabular}

Note. $N=108$ 
Table 4.

Logistic Regression with Pain Medication Knowledge Score Predicting the Likelihood of Expecting an Opioid Medication

\begin{tabular}{|c|c|c|c|c|c|c|c|c|c|}
\hline \multicolumn{10}{|c|}{ Variables in the Equation } \\
\hline & & \multirow[b]{2}{*}{ B } & \multirow[b]{2}{*}{ S.E. } & \multirow[b]{2}{*}{ Wald } & \multirow[b]{2}{*}{ df } & \multirow[b]{2}{*}{ Sig. } & \multirow[b]{2}{*}{$\operatorname{Exp}(B)$} & \multicolumn{2}{|c|}{ 95\% C.I.for EXP(B) } \\
\hline & & & & & & & & Lower & Upper \\
\hline \multirow[t]{2}{*}{ Step $1^{a}$} & Knowledge & .117 & .101 & 1.326 & 1 & .250 & 1.124 & .921 & 1.370 \\
\hline & Constant & -1.096 & .569 & 3.713 & 1 & .054 & .334 & & \\
\hline
\end{tabular}

a. Variable(s) entered on step 1: Knowledge.

Note. $N=108$ 